\title{
Proteomic analysis and immunodetection of the bovine milk osteopontin isoforms
}

\author{
N. Bissonnette,${ }^{*}{ }^{1}$ P. L. Dudemaine,${ }^{*} \dagger$ C. Thibault, ${ }^{*}$ and G. Robitaille‡ \\ *Dairy and Swine Research and Development Centre, Agriculture and Agri-Food Canada, Sherbrooke, Québec, Canada J1M 1 Z3 \\ †Département de Biochimie, Faculté de médecine et des sciences de la santé, Université de Sherbrooke, Sherbrooke, Québec, Canada J1H 5N4 \\ ¥Food Research and Development Centre, Agriculture and Agri-Food Canada, St-Hyacinthe, Québec, Canada J2S 8E3
}

\section{ABSTRACT}

The aim of this study was to characterize the osteopontin (OPN) secreted in bovine milk and to determine whether the different forms are the product of spliced variants. Spliced variants of the human gene and secreted osteopontin isoforms have been reported in human tumor tissue. In bovine milk, we identified 2 major forms: one corresponding to the full-length coding transcript and a truncated version of this form. No alternative spliced transcripts were detected in the lactating mammary gland tissue, in milk somatic cells, or in peripheral blood immune cells. The $60-\mathrm{kDa}$ bovine osteopontin (bOPN) and a truncated $40-\mathrm{kDa}$ protein isoform were confirmed by mass spectrometry and further characterized by immunoblotting using a panel of 6 antibodies targeting different domains of the protein. Of the 3 human anti-OPN antibodies targeting the $\mathrm{N}$-terminal segment of the protein, only one detected all forms on sodium dodecyl sulfate-PAGE; one human anti-OPN antibody failed to detect bOPN, whereas the other detected only the $60-\mathrm{kDa}$ protein, albeit barely in its phosphorylated form. Detection was generally more sensitive when the $60-\mathrm{kDa}$ protein was dephosphorylated. Two polyclonal antibodies raised against bOPN were tested: one targeting the milk-purified bOPN (bOPN-121) and one targeting a bovine epitope (synthetic peptide) corresponding to a carboxy-terminal domain of the protein (bOPN-117). The bOPN-121 antibody detected all forms irrespective of the phosphorylation status of bOPN. The bOPN-117 and the mouse anti-human OPN (hOPN-4) antibodies, which recognized different domains of the carboxy-terminal segment of the protein, also preferentially detected the dephosphorylated $60-\mathrm{kDa}$ protein. Whereas phosphorylation had a major effect on detection for several antibodies, deglycosylation slightly decreased immunodetection for the tested antibodies. In particular, phos-

Received July 20, 2011.

Accepted October 8, 2011.

${ }^{1}$ Corresponding author: nathalie.bissonnette@agr.gc.ca phorylation is the major posttranslational modification that influenced the weak detection capacity of several antibodies. This fact needs to be taken into account for immunodetection of milk content. In conclusion, the OPN forms secreted in bovine milk are not the product of alternative splicing. The $40-\mathrm{kDa}$ protein appears to be a truncated hypophosphorylated variant of the fulllength $60-\mathrm{kDa}$ form, which is highly phosphorylated. Together, the proteomic and immunoblotting analyses used to characterize bovine milk OPN revealed the complex nature of the bovine milk OPN forms.

Key words: osteopontin, dairy milk, gene expression, posttranslational modifications

\section{INTRODUCTION}

Osteopontin (OPN) is an intracellular protein (Zohar et al., 1997; Shinohara et al., 2008) as well as a secreted protein synthesized by, or found in, a variety of cells and tissues, including the mammary gland, kidney, blood, and immune organs. Osteopontin plays numerous roles that can vary according to its cellular origin but it also performs different activities derived from its specific domains. It interacts with a variety of cell surface receptors (e.g., the integrin receptor $\alpha_{V} \beta_{3}$ ) and multiple mineral or organic ligands, such as CD44, factor $\mathrm{H}$, fibrinogen, and hydroxyapatite (for the most recent reviews, see Kazanecki et al., 2007; Lund et al., 2009). Osteopontin is now recognized as an important proinflammatory cytokine with pleiotropic functions (Wang and Denhardt, 2008). It has been detected as an early T-cell activating factor during bacterial infection (Fet et al., 1989; Alain et al., 2009). Secreted by macrophages, its accumulation at tissue surfaces may be beneficial for phagocytosis of cell debris during wound healing (McKee and Nanci, 1996) or during brain stroke recovery (Shin et al., 2010). Phosphorylation state also modulates OPN functions, including integrin-mediated adhesion (Ek-Rylander et al., 1994), mineralization (Zhu et al., 2001), cellular migration (Andersson et al., 2003), immune responses (Weber et al., 2002), and autoimmune pathology (Behrens and Graham, 2011). 
The final configuration of the protein thus influences its bioactivity. Although OPN performs beneficial functions, it has also been linked to cancer-associated mechanisms, such as tumorigenesis and proliferation (Liu et al., 2009), which may explain the metastatic ability of cancer cells.

Pleiotropic functions of OPN have been demonstrated, but recently its abnormal expression in various metastasis-associated tissues in humans has raised concern about the presence of certain splice variants. In humans, 3 spliced variants of the OPN, which is encoded by the SPP 1 gene, have been detected in different tissues (Crivello and Delvin, 1992; He et al., 2006; Chae et al., 2009). Isoform-c, the shorter protein variant, is specifically expressed in tumor tissue such as ovarian (Tilli et al., 2011), breast (Mirza et al., 2008), and hepatocellular (Chae et al., 2009) carcinoma cells. Because of the presence of specific isoforms and their positive correlation with numerous pathological situations, OPN is considered a marker of human metastasis (Plumer et al., 2008).

Bovine OPN is secreted into body fluids (bile, urine, semen, saliva) and in substantial amounts $(8-22 \mathrm{mg} / \mathrm{L})$ in bovine milk (Sorensen and Petersen, 1993b; Bayless et al., 1997; Kumura et al., 2004), being 10 times more concentrated in colostrum (Kumura et al., 2004). In bovine milk, several isoforms of OPN have been detected by immunoblotting (Kumura et al., 2004). The objective of this study was to better characterize the OPN isoforms found in bovine milk and to determine whether these isoforms are alternative spliced variants. Of the main secreted OPN proteins in bovine milk, we found that one was highly phosphorylated and corresponded to the translated full-length coding sequence, and the second, a low molecular weight variant, was truncated into the carboxy (C)-terminal part of the OPN protein, a finding predicted because of the absence of C-terminal immunodetection (Kumura et al., 2004) and further characterized in the present study by mass spectroscopy. No spliced variant of the $S P P 1$ transcript was detected. Only one isoform was detected in lactating mammary gland tissue, milk somatic cells, and peripheral blood cells. Bovine milk does not contain the equivalent of the human metastasis-prone isoforms. Further research is required to determine the bioactivity of these different isoforms and to unravel the complexities of OPN biology.

\section{MATERIALS AND METHODS}

\section{OPN Isolation and Treatment}

Osteopontin from bovine milk was purified by ionexchange chromatography and hydrophobic chroma- tography as described elsewhere (Bayless et al., 1997). Briefly, acid whey was adsorbed to Q-sepharose anionexchange resin (GE Healthcare, Baie d'Urfé, Canada) at $\mathrm{pH} 5$ in acetate buffer $(100 \mathrm{~m} M$ sodium acetate, $\mathrm{pH}$ 5.0) and eluted using a step-wise gradient at 0.3 $M \mathrm{NaCl}$ in acetate buffer. The OPN-rich fraction was further purified by a second chromatography run with a linear gradient of $\mathrm{NaCl}$ from 0 to $1 M$ in acetate buffer. The OPN fractions were pooled and the $\mathrm{NaCl}$ concentration was adjusted to $4 M(\mathrm{pH} 7.4)$ and absorbed onto a phenyl-sepharose column (GE Healthcare). The column was washed with 10 volumes of a solution of $4 M \mathrm{NaCl}$ in $10 \mathrm{~m} M$ phosphate buffer (pH 7.4), and OPN was eluted using $2 \mathrm{M} \mathrm{NaCl}$ phosphate buffers. Fractions containing OPN were dialyzed against deionized water and lyophilized. Dephosphorylation of OPN was performed using Lambda protein phosphatase (PP) following the manufacturer's recommendations (New England BioLabs Inc., Ipswich, MA). Cleavage with thrombin (thrombin from bovine plasma, SigmaAldrich, Oakville, ON, Canada) was performed as recommended. The bovine OPN (bOPN) was treated with endo- $\alpha$ - $N$-acetylgalactosaminidase, $o$-glycosidase (New England BioLabs Inc.) and neuraminidase (New England BioLabs Inc.), or the PNGase F $N$-deglycosylase (New England BioLabs Inc.), as recommended. Treatments were performed in the presence of protease inhibitors (Sigma-Aldrich) except for the thrombin cleavage. Controls included incubation in the absence of enzyme. Samples were subsequently analyzed by SDS-PAGE followed by immunoblotting.

\section{Proteomic Analysis}

Proteomic analysis using liquid chromatography coupled with tandem MS (LC-MS/MS) was performed at the Proteomic Platform, McGill University, and at the Génome Québec Innovation Centre (McGill University, Montreal, Canada). Five micrograms of total purified milk bOPN were fractionated by SDS-PAGE onto a 12 to $15 \%$ polyacrylamide. Protein band visualization in gel was done after silver staining. Bands I and II were excised separately on a robotic workstation (ProXCISION Proteomics Gel Cutting Robot, PerkinElmer Life and Analytical Sciences, Woodbridge, ON, Canada). Proteins from the gel bands were subjected to reduction, cysteine-alkylation, and in-gel tryptic digestion in a MassPrep Workstation (Waters Corp., Mississauga, ON, Canada) as described previously (Wasiak et al., 2002) with minor modifications. Briefly, reduction was performed in the dark; effect alkylation was done by incubation with $55 \mathrm{mM}$ iodoacetamide for $20 \mathrm{~min}$, and protein digestion was done for $4.5 \mathrm{~h}$ with $6 \mathrm{ng} / \mu \mathrm{L}$ of Trypsin Gold (Promega, Madison, WI) in $100 \mathrm{mM}$ 
$\left(\mathrm{NH}_{4}\right)_{2} \mathrm{CO}_{3}$. After digestion, the samples were analyzed by nanoflow LC-MS as described elsewhere (Marsolais et al., 2010) using an acetonitrile:water:formic acid linear gradient from 10:90:0.1 to 95:5:0.1 ( vol/vol/vol) for $30 \mathrm{~min}$. Mass spectrometric data were acquired using a Micromass QTof mass spectrometer (Waters Corp.). Data-dependent analysis was done on the most intense ions from each full-scan MS with dynamic exclusion for $60 \mathrm{~s}$. Simple MS scan range was from 350 to 1,600 $m / z$ for $1 \mathrm{~s}$, and MS/MS data were acquired for up to $31 \mathrm{~s}$ scans from 50 to $2,000 \mathrm{~m} / z$. Peak selection for MS/MS list generation was done with Mascot Distiller 2.3 (Matrixscience, Boston, MA). Protein identification was done with Mascot 2.3 against a UniProt_database from 20091124 filtered for mammalian proteins (268,748 entries) using trypsin as digestion enzyme with one miscleavage allowed, carboxyamidomethylation of cysteines as fixed modification, methionine oxidation as variable modification, and 0.5 Da precursor and 0.5 fragment search tolerances. Scaffold (Scaffold_2_07 version, Proteome Software Inc., Portland, OR) was used to validate MS/MS-based peptide and protein identifications. Peptide identifications were accepted if they exceeded specific database search engine thresholds. Mascot identifications required ion minus identity scores greater than zero. Protein identifications were accepted if they contained at least one identified peptide. Proteins that contained similar peptides and could not be differentiated based on MS/MS analysis alone were grouped to satisfy the principles of parsimony. Peptide hydrophobicity was performed using the ExPASy Proteomics tools (http://ca.expasy.org/ tools/). Hydrophobicity of the peptide was determined without taking any posttranslational modifications into account, using ProtScale according to the algorithm developed by Kyte and Doolittle (1982), and confirmed using algorithms developed by Roseman (1988) and Abraham and Leo (1987).

\section{Transcript Analysis of Bovine SPP1 Gene}

Biopsies of mammary gland tissue were donated by Pierre Lacasse (Dairy and Swine Research and Development Centre, Sherbrooke, QC, Canada) and were taken from early (20 d), mid (150 d), and late (206 d) lactating cows as described previously (Bernier-Dodier et al., 2010). Analysis was performed on a pool of RNA tissue from 3 cows. Milk somatic cells and peripheral blood cells were prepared from 15 cows as described elsewhere (Alain et al., 2009). Monocytes were isolated by adherence as described elsewhere (Kabara et al., 2010). Extraction of RNA was carried out using TRIzol Reagent (Invitrogen Canada Inc., Burlington, ON, Canada) followed by DNase I treatment (Ambion Inc., Foster City,
$\mathrm{CA}$ ), as recommended by the manufacturer. Reverse transcription (RT) was performed with $1.5 \mu \mathrm{g}$ of RNA according to the SuperScript II RT procedure (Invitrogen). Each RT assay was performed in a $20-\mu \mathrm{L}$ reaction. The RT reaction was primed to generate the full-length transcript using $500 \mathrm{ng}$ of oligo(dT)12-18 (Invitrogen) or using inner gene-specific primers, thus producing SPP1 transcript, to target the corresponding human spliced region using 20 pmol of $5^{\prime}-{ }^{512}$ TCATTTGCGCTTTCCGTAGG ${ }^{493}-3^{\prime}$, or $5^{\prime}{ }_{-}{ }^{508}$ GGCGGAACTTCTTAGATCTTGACTT ${ }^{544}-3^{\prime}$, both located in exon 6 . The PCR reactions were performed by nested PCR using all combinations of one of the forward SPP1-specific primers $\quad\left[5^{\prime}-{ }^{5111}\right.$ ATTCTGGGAGATCCTGGTTGT$\mathrm{CAG}^{5134}-3^{\prime}$ (position according to GenBank accession no. AY878328, located 39 nucleotides upstream of the first untranslated exon 1), $5^{\prime}-{ }^{19}$ GACTGGACTCTTCTC$\mathrm{GCC}^{36}-3^{\prime}$ (located in the untranslated exon 1 of $S P P 1$ ), $5^{\prime}{ }^{61}{ }^{2}$ ACCATGAGAATTGCAGTGATTTGCT ${ }^{85}{ }_{-3}{ }^{\prime}$ (targeting exon 2 and including the peptide signal sequence)] and one of the following reverse primers, when appropriate (i.e., within the reverse transcribed sequence): $\quad 5^{\prime}-{ }^{479} \mathrm{AAAACTGCGATTGTTGGAATAT-}$ $\mathrm{CAG}^{455}-3^{\prime}$ (in exon 6) and $5^{\prime}-{ }^{901}$ TTCAATTGACCTCAGAAGAGGCAC ${ }^{878}-3^{\prime}$ and $5^{\prime}-{ }^{1083}$ AGGGTGTTACCATGAAGCCACACA ${ }^{1060}-3^{\prime}$ (both targeting exon 7 ). Respective positions (supershift) are given according to the reference sequence of the NCBI RefSeq RNA database (GenBank accession no. NM_174187.2) unless otherwise indicated. The PCR reactions were carried out using $2 \mu \mathrm{L}$ of $\mathrm{RT}$ reaction in a $50-\mu \mathrm{L}$ reaction volume using Taq polymerase (BioShop Canada Inc., Burlington, ON, Canada). The following cycling conditions were used for all amplifications: 2 min at $94^{\circ} \mathrm{C}$, followed by 40 cycles of $30 \mathrm{~s}$ at $94^{\circ} \mathrm{C}, 30 \mathrm{~s}$ at $59^{\circ} \mathrm{C}$, and $1.5 \mathrm{~min}$ at $72^{\circ} \mathrm{C}$, and ending with $5 \mathrm{~min}$ at $72^{\circ} \mathrm{C}$. The PCR products were visualized by $1.25 \%$ agarose gel electrophoresis and amplicon confirmed by sequencing as described previously (Alain et al., 2009).

\section{Antibodies}

Antibody epitope mapping is presented in Figure 1. The polyclonal hOPN-4 antibody (gift from S. Kon, Hokkaido University, Japan) maps to the C-terminal (peptide 4: $\mathrm{Lys}^{296}-\mathrm{Asn}^{314}$ ) of human OPN (Kon et al., 2002). The monoclonal antibodies MAB193P, MAB194P, and MAB197P were from Maine Biotechnology Services (Portland, ME). The bOPN-121 and bOPN-117 were custom-made polyclonal antibodies (Biotechnology Research Institute, Montreal, QC, Canada; http://www.irb.cnrc.gc.ca), using as immunogens the purified bOPN protein and the synthetic peptide ${ }^{150}$ KFRRSNVQSPDATEEDFT ${ }^{167}$, respectively. Rabbit 


\begin{tabular}{|c|c|c|c|}
\hline ovine & 1 & $\begin{array}{l}\text { MRIAVICECLLGIASALPVKPTSSGSSEEKQLNNKYPDAVAIWLKPDPSQKQTFLTPQ NS } \\
\text { MRIAVICFCLLGI A PVK SGSSEEKQLN KYPDAVA WL PDPSQKQ L PQ N }\end{array}$ & 60 \\
\hline human & 1 & MRIAVICFCLLGITCAIPVKQADSGSSEEKQLYNKYPDAVATWLNPDPSQKQNLLAPQ NA & 60 \\
\hline bovine & 61 & 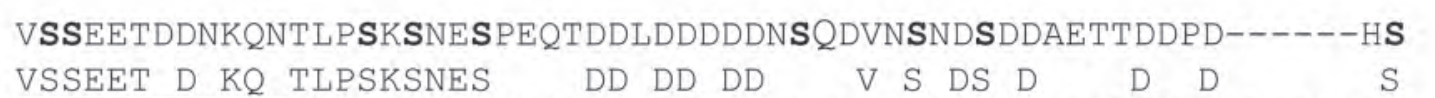 & \\
\hline human & 61 & $\frac{\text { VSSEETNDFKQETLPSKSNESHDHMDDMDDEDDDD-HVDSQDSIDSNDSDDVDDTDDSHQS }}{\text { MAB194P }}$ & \\
\hline bovine & 116 & 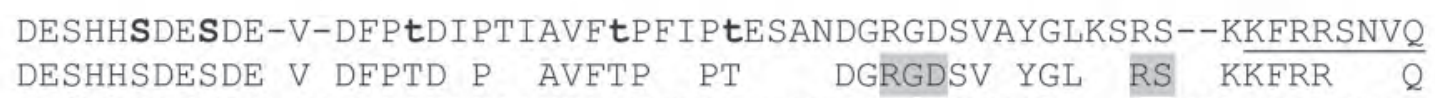 & 3 \\
\hline human & 121 & $\begin{array}{l}\text { DESHHSDESDELVtDFPtDLPAtEVFtPVVPtVDTYDGRGDSVVYGL--RSKSKKERRPDIQ } \\
\text { bOPN-117 }\end{array}$ & 30 \\
\hline bovine & 174 & $\begin{array}{l}\text { SPDATEEDFTSHIESEEMHDAPK---n } \\
\text { PDAT ED TSH ESEE A K }\end{array}$ & \\
\hline human & 181 & YPDATDEDITSHMESEELNGAYKAIPVAQDLNAPSDWDSRGKDSYETSQLDDQSAETHSH & \\
\hline bovine & 212 & 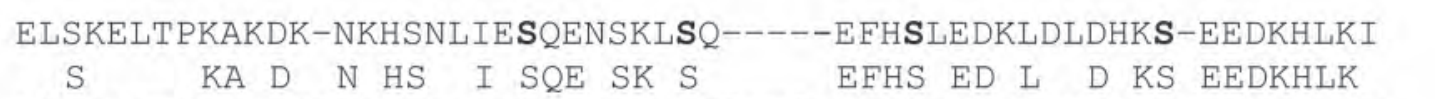 & \\
\hline human & 241 & KQSRLYKRKANDESNEHSDVIDSQELSKVSREFHSHEFHSHEDMLVVDPKSKEEDKHLKE & \\
\hline bovine & 265 & $\begin{array}{l}\text { RISHELDSASSEVN } \\
\text { RISHELDSASSEVN }\end{array}$ & \\
\hline human & 301 & $\frac{\text { RISHELDSASSEVN }}{\text { hOPN-4/1B20 }}$ & \\
\hline
\end{tabular}

Figure 1. Mapping of the putative posttranslational modification sites and the antibody-associated epitopes of the bovine and human osteopontin (OPN) protein sequences. Epitopes of the human antibodies (MAB193P, MAB194P, MAB197P, and hOPN-4) and the peptide sequence used to raise the bovine bOPN-117 antibody are underlined. The peptide signal (first $16 \mathrm{AA}$ ) is shown in italics. The mature bovine protein and the longest human isoform protein contain, respectively, 262 and 298 AA (NCBI GenBank accession nos. NP_776612.1 and NP_001035147). Putative position of the 27 phosphorylated serine residues and the single phosphorylated threonine residue for bOPN sequences (GenBank accession no. NM_174187.2) as well as the 32 phosphoserines and the 2 phosphothreonines for human milk OPN sequences (GenBank accession no. NM_001040058.1) are presented in bold letters. Three threonine residues (positions 131, 140, and 145, in bold) are modified for bOPN, whereas 5 residues $\left(\mathrm{Thr}^{118}\right.$, $\mathrm{Thr}^{122}$, $\mathrm{Thr}^{127}$, $\mathrm{Thr}^{131}$, and $\mathrm{Thr}^{136}$ ) are modified for human protein; they are putative glycosylated sites (lowercase letters). The cell attachment site (RGD) to integrin and the position of the thrombin cleavage site (RS), both highlighted, are conserved between species. In humans, 2 more splice variants, OPN-b and OPN-c, are found, which respectively lack exon 5 (14 AA, position Asn ${ }^{59}$ to Glu ${ }^{72}$ ) and exon 4 (27 AA, position $\operatorname{Leu}^{32}$ to $\mathrm{Gln}^{58}$ ); exons 4 and 5 are represented in adjacent boxes, and the dashed line indicates the continuity of exon 5 .

antiserum was used for immunoblotting. The specificity of bOPN-117 was confirmed by competition assays using the purified bOPN (50 or $500 \mathrm{ng}$ ) or the synthetic peptide $(10$ or $100 \mu M)$, which were compared using mock peptides $(10$ or $100 \mu M)$ from Biotechnology Research Institute. Milk-derived bOPN (cat. no. 109-OP050/C) and recombinant human OPN (rhOPN, cat. no. 1433-OP-050/CF) were purchased from R\&D Systems (Minneapolis, MN).

\section{SDS-PAGE and Immunodetection}

Sodium dodecyl sulfate-PAGE was performed on acrylamide gels (Bio-Rad Laboratories Ltd., Missis- sauga, ON, Canada) according to the method of Laemmli (1970) under reducing conditions. Samples were run with a molecular weight marker (Precision Plus protein standards, Bio-Rad Laboratories Inc.). Gels were stained for total protein using a silver staining kit (FastSilver, GBiosciences, St. Louis, MO) and for glycosylated proteins using a glycoprotein staining kit (GBiosciences). Prior to electrophoresis, bovine or human milk was defatted by centrifugation at $1,800 \times g$ for $15 \mathrm{~min}$ at $4^{\circ} \mathrm{C}$ followed by a centrifugation at 21,460 $\times g$ for $90 \mathrm{~min}$ at $4^{\circ} \mathrm{C}$. Aliquots of total proteins were kept frozen $\left(-80^{\circ} \mathrm{C}\right)$ until analysis. Proteins were transferred onto Immuno-Blot PDVF membrane (Bio-Rad Laboratories Ltd.). For the assay of dephosphorylation 
on membrane before immunodetection, the membranes were incubated with Lambda PP as described elsewhere (Richter et al., 2004). Membranes were blocked overnight with Tris-buffered saline $(150 \mathrm{mM} \mathrm{NaCl}, 10 \mathrm{~m} M$ Tris-HCl, pH 7.4) containing $0.1 \%$ (vol/vol) Tween 20 (TBST) and 3\% (wt/vol) blocking reagent (BSA; BioShop Canada Inc.). The membranes were then incubated for $1 \mathrm{~h}$ at room temperature in TBST-BSA containing the primary antibody. The membranes were washed 3 times for $5 \mathrm{~min}$ in TBST and incubated with the secondary antibody for $1 \mathrm{~h}$ at room temperature, and finally washed 3 times for $15 \mathrm{~min}$ before revelation. The primary antibodies MAB193P, MAB194P, and MAB197P were diluted 1:1,000, unless otherwise stated. They were detected using ECL anti-mouse IgG horseradish peroxidase-linked whole antibodies (GE Healthcare) diluted $1: 10,000$ in TBST. The primary antibody hOPN-4 was diluted $1: 100$ and bOPN-117 and bOPN-121 were diluted 1:500. These primary antibodies were detected using ECL anti-rabbit IgG, horseradish peroxidase-linked whole antibodies (GE Healthcare). Proteins were detected using ECL Plus Western Blotting Detection Reagent (GE Healthcare). Images were analyzed using Alpha Innotech FluorChem SP (Cell BioSciences, Toronto, ON, Canada).

\section{Production of Recombinant OPN}

The cDNA was prepared by reverse transcription using $2 \mu \mathrm{g}$ of mammary gland tissue as described previously (Alain et al., 2009). The OPN cDNA (SPP1) was amplified by a proofreading Taq polymerase (BioShop Canada Inc.) using the forward primer 5'-CGGGATCCAGAATTGCAGTGATTTGCTTCTG- $3^{\prime}$ and the reverse primer 5'-CCCAAGCTTGGTGTTACCATGAAGCCACAC-3'. The amplicon was purified using Nucleo Spin Extract II (Mackerey-Nagel, Bethlehem, PA), and treated with BamHI and HindIII restriction enzymes (New England BioLabs Inc.). The BamHIHindIII restriction fragment was purified and cloned into the pQE-30 expression vector (Qiagen Inc., Toronto, ON, Canada) according to the manufacturer's instructions. Sequence of SPP1 was confirmed according to GenBank accession no. NM_178187.2 by sequencing performed using BigDye Terminator chemistry and analyzed using the 3100-Avant Genetic Analyzer (Applied Biosystems, Foster City, CA). The recombinant bOPN ( $\mathbf{r b O P N})$ protein was produced in Escherichia coli (strain M15[pREP4], Qiagen Inc.) following isopropyl- $\beta$-D-thio-galactoside (Sigma-Aldrich) induction, purified onto Ni-NTA resin (Sigma-Aldrich) according to the manufacturer's instructions (Qiagen Inc.) and dialyzed against PBS. Aliquots were stored at $-80^{\circ} \mathrm{C}$.

\section{RESULTS}

\section{Proteomic Analysis of Bovine Milk OPN}

Bovine OPN was purified from milk as described under "Materials and Methods." For the proteomic analysis, the purified bOPN was dephosphorylated, because analysis of phosphopeptides by electrospray is complicated by the presence of phosphate groups that influence the charge and mass of the peptide. The dephosphorylated OPN extract was fractionated by SDS-PAGE and visualized by silver staining (Figure $2 \mathrm{~A}$ ) and the 2 major bands were analyzed using the in-gel digestion option, followed by LC-MS/MS and matrix-assisted laser desorption/ionization (MALDI) analysis. Results are summarized in Table 1 . The high molecular weight protein (band I, Figure 2A) included the end-tryptic Ile ${ }^{266}-\mathrm{Asn}^{278}$ peptide and corresponded to the full-length protein. Analysis of this band I protein by LC-MS/MS provided information for $48 \%$ of the full-length protein. This limited coverage can be explained by detection impairment of the large tryptic peptide $\left(\mathrm{Ser}^{78}-\mathrm{Arg}^{152}\right.$, according to NCBI protein accession no. NP_776612.1), which corresponded to $29 \%$ of the mature protein. This $8.2-\mathrm{kDa}$ peptide was probably difficult to extract from the gel, because the peptide is long (75 AA), highly hydrophobic, and contains the putative glycosylated sites (Sorensen et al., 1995). The LC-MS/MS profile of the $40-\mathrm{kDa}$ protein (band II on Figure 2A) indicated that both proteins had similar Nterminal portions and that band II represented a truncated version of the full-length (band I) mature protein. The last peptide detected in band II and shared with protein band I was Gly ${ }^{154}$-Lys ${ }^{163}$. The failure to detect the tryptic peptide SNVQSPDATEEDFTSHIESEEMHDAPK following 3 different LC-MS/MS profile analyses suggested that the truncated protein was cleaved into that peptide. The MS analysis revealed that all exons present in mature protein were detected and confirmed that the low molecular weight protein (band II) was a truncated version of the full-length bOPN.

\section{Bovine SPP1 Transcript}

To confirm that the truncated bOPN isoform in milk originated from a single transcript and not from spliced variants, the transcript profiles of various bovine mammary tissues were analyzed by RT-PCR. The $\mathrm{RT}$ reaction was primed using gene-specific primer (targeting exon 6) or an oligo(dT). The cDNA encompassed exons 3 and 4 , which are alternatively spliced in human tumors. The SPP1 gene-specific cDNA and the full-length cDNA pool analyzed using a panel of gene-specific primers did not show evidence of tran- 
A

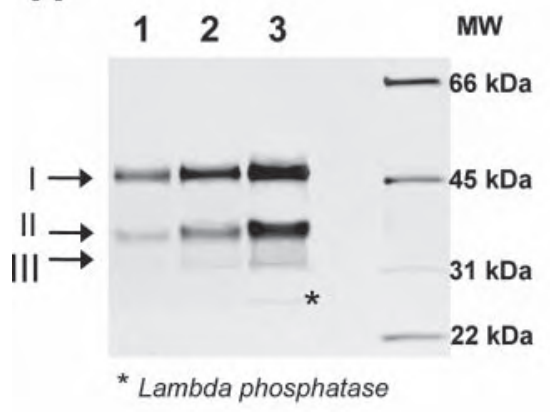

B

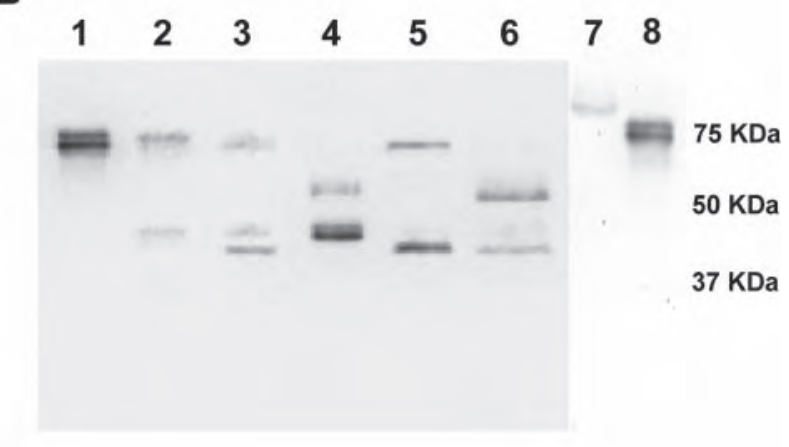

Figure 2. Osteopontin (OPN) in bovine milk. Molecular weight (MW) fractionation by SDS-PAGE followed by (A) silver staining and (B) immunoblotting using the monoclonal MAB193P antibody. (A) The purified bOPN treated by Lambda protein phosphatase (PP) was analyzed by $4-12 \%$ gradient SDS-PAGE and loaded as $250 \mathrm{ng}$ (lane 1), $500 \mathrm{ng}$ (lane 2), and $1 \mu \mathrm{g}$ (lane 3). Bands I to II were in-gel digested and further analyzed by liquid chromatography-tandem mass spectrometry. (B) Samples loaded onto the 10\% SDS-PAGE were as follows: commercial recombinant human OPN (50 ng, lanes 1 and 8), commercial bovine (b)OPN (150 ng, lane 2), purified bOPN (150 ng, lane 3) and Lambda protein phosphatase (PP) dephosphorylated bOPN (150 ng, lane 4), $10 \mu \mathrm{g}$ each of bovine milk (lane 5) or Lambda PP treated milk proteins (lane 6), and human milk $(1 \mu \mathrm{g}$, lane 7$)$.

script variants (data not shown). A single transcript was always detected starting from the $5^{\prime}$-untranslated region (UTR). Alternative splicing was not detected, either in secreting tissue of the bovine lactating mammary gland during any of the lactation periods tested or in blood or milk immune cells (Figure 3).

\section{Characterization of Posttranslational Modifications by Immunoblotting}

Bovine and human OPN and milk proteins were analyzed by immunoblotting. Whereas the high molecular weight form was detected in human milk (Figure 2B,

Table 1. Liquid chromatography-tandem mass spectrometry of osteopontin (OPN)

\begin{tabular}{|c|c|c|c|c|}
\hline $\begin{array}{l}\text { Protein } \\
\text { (band no.) }\end{array}$ & Peptide $^{1}$ & $\begin{array}{c}\text { Peptide } \\
\text { start index }\end{array}$ & $\begin{array}{c}\text { Peptide } \\
\text { stop index }\end{array}$ & $\begin{array}{l}\text { Exon } \\
\text { no. }\end{array}$ \\
\hline \multirow[t]{5}{*}{ II } & LPVKPTSSGSSEEK $^{4}$ & 17 & 30 & 3 \\
\hline & YPDAVATWLKPDPSQK & 36 & 51 & 4 \\
\hline & QTFLAPQNSVSSEETDDNK & 52 & 70 & $4-5$ \\
\hline & QTFLAPQNSVSSEETDDNKQNTLPSK & 52 & 77 & $4-5$ \\
\hline & GDSVAYGLK & 153 & 161 & 6 \\
\hline $\begin{array}{l}\text { Percentage peptide identification (coverage) } \\
\text { excluding peptide signal }\end{array}$ & & & $(81 / 262)$ & $31 \%$ \\
\hline \multirow[t]{10}{*}{ I } & QLNNKYPDAVATWLKPDPSQK & 31 & 51 & 4 \\
\hline & YPDAVATWLKPDPSQK & 36 & 51 & 4 \\
\hline & QTFLAPQNSVSSEETDDNK & 52 & 70 & $4-5$ \\
\hline & QTFLAPQNSVSSEETDDNKQNTLPSK & 52 & 77 & $4-5$ \\
\hline & GDSVAYGLK & 153 & 161 & 6 \\
\hline & SNVQSPDATEEDFTSHIESEEMHDAPK & 170 & 196 & $6-7$ \\
\hline & HSNLIESQENSK & 227 & 238 & 7 \\
\hline & LSQEFHSLEDK & 239 & 249 & 7 \\
\hline & LSQEFHSLEDKLDLDHK & 239 & 255 & 7 \\
\hline & ISHELDSASSEVN & 266 & 278 & 7 \\
\hline $\begin{array}{l}\text { Percentage peptide identification } \\
\text { (coverage) excluding peptide signal }\end{array}$ & & & $(125 / 262)$ & $48 \%$ \\
\hline
\end{tabular}

\footnotetext{
${ }^{1}$ Identification probabilities totaled $100 \%$.

${ }^{2}$ Positions refer to NCBI protein accession no. NP_776612.1.

${ }^{3}$ Exon 1 is not translated and exon 2 encompasses the signal peptide, which is not found in mature protein, plus the first 2 amino acids (LP) of the mature protein. Exon 3 corresponds to VKPTSSGSSEEK; exon 4, QLNNKYPDAVAIWLKPDPSQKQTFLTP; exon 5, QNSVSSEETDDNKQ; exon 6, NTLPSKSNESPEQTDDLDDDDDNSQDVNSNDSDDAETTDDPDHSDESHHSDESDEVDFPTDIPTIAVFTPFIPTESANDGRGDSV AYGLKSRSKKFRRSNV; and exon 7 corresponds to the QSPDATEEDFTSHIESEEMHDAPKKTSQLTDHSKETNSSELSKELTPKA KDKNKHSNLIESQENSKLSQEFHSLEDKLDLDHKSEEDKHLKIRISHELDSASSEVN fragment of the full-length mature OPN, as reported in the GenBank accession no. AY878328.1 sequence.

${ }^{4}$ Band II was further analyzed by matrix-assisted laser desorption/ionization (MALDI) and peptide 17-30 was identified.
} 


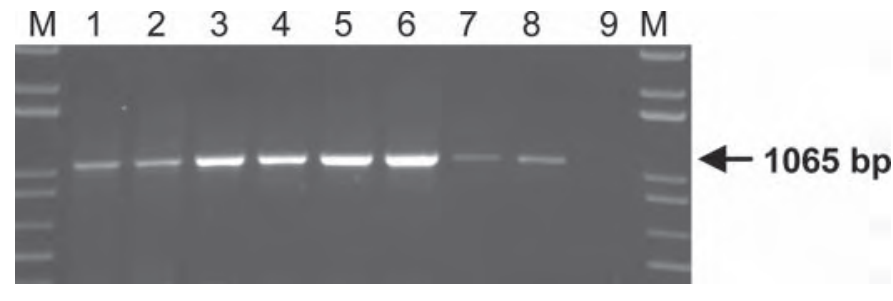

Figure 3. Absence of alternative splicing for SPP1 transcript. Reverse transcription-PCR was performed using total RNA from mammary gland (lanes 1, 2, and 3) and milk somatic cells (lanes 4, 5, and 6), isolated at 3 (lane 1 and 4), 22 (lanes 2 and 5), and 30 (lanes 3 and 6) wk of lactation, and using peripheral blood mononuclear cell (lane 7) and monocyte (lane 8) transcripts. The primers $5^{\prime}{ }^{19}{ }^{-G A C T G G A C T C T T C T C G C C ~}{ }^{36}-3^{\prime}$ and $5^{\prime}-{ }^{1083}$ AGGGTGTTACCATGAAGCCACACA ${ }^{1060}-3^{\prime}$ encompassed the coding sequence; PCR was performed in parallel with a no template control (lane 9). Results were visualized by $1.25 \%$ agarose gel electrophoresis; lane $\mathrm{M}=$ molecular marker (1 Kb Plus DNA Ladder, Invitrogen, Burlington, ON, Canada).

lane 7), several shorter isoforms were detected in bovine milk. As shown in Figure 2B (lanes 3 and 5), the monoclonal human MAB193P antibody cross-reacted with milk bOPN isoforms: the $60-\mathrm{kDa}$ mature protein and the doublet migrating around $40 \mathrm{kDa}$. Moreover, both intact $(60 \mathrm{kDa})$ and truncated proteins $(40-\mathrm{kDa}$ doublet) were detected in milk from other cows (data not shown). The $60-$ and $40-\mathrm{kDa}$ proteins were also detected in commercial milk purified bOPN (Figure 2B, lane 2). Truncated human isoform was not detected, either in the commercial human OPN or in the human milk protein extract.

Phosphorylation had a major effect on the migration of the $60-\mathrm{kDa}$ protein, given that dephosphorylation induced a significant 10-kDa shift on SDS-PAGE (Figure 2B, lanes 5 and 6), whereas no notable shift was observed for the $40-\mathrm{kDa}$ bOPN protein. Similar results were observed with bOPN purified from milk, but one of the 40-kDa doublet bands that could be seen more clearly with purified bOPN proteins was also affected by the dephosphorylation treatment (Figure 2B, lanes 3 and 4). With regard to the apparent molecular weight of the milk bOPN, we observed a discrepancy in the size of OPN proteins depending on the type of acrylamide gradient used for SDS-PAGE. For example, the full-length dephosphorylated protein migrated at $45 \mathrm{kDa}$ on 4 to $12 \%$ gradient SDS-PAGE (Figure 2A), but at $50 \mathrm{kDa}$ in $12 \%$ acrylamide (Figure 2B, lane 4 ). This is consistent with the finding of an earlier report on OPN (Butler, 1989). In general, the difference in SDS-PAGE between the 2 major forms secreted in milk was $20 \mathrm{kDa}$; the difference decreased to $10 \mathrm{kDa}$ when proteins were dephosphorylated before SDSPAGE analysis. The posttranslational modifications of the protein affected not only migration of the protein bands in SDS-PAGE but also immunodetection. In fact, hOPN-4 (C-terminal detection, Figure 1) barely revealed intact bOPN but efficiently detected the 60 $\mathrm{kDa}$ protein when dephosphorylation was carried out on a polyvinylidene fluoride membrane after Western blotting. The limitation of hOPN-4 for detecting the native $60-\mathrm{kDa}$ bOPN protein was thus released following membrane dephosphorylation (data not shown). Moreover, this confirmed the MS/MS analysis: the truncated $40-\mathrm{kDa}$ protein lacked the C-terminal portion and was not detected by hOPN-4. The $\sim 10-\mathrm{kDa}$ shift in SDS-PAGE was attributable to the phosphate moiety removed following Lambda PP treatment of the $60-\mathrm{kDa}$ protein. This difference observed in SDS-PAGE between the 2 phosphorylation states was confirmed by loading both dephosphorylated and nontreated full-length bOPN in the same lane, which were both detected following dephosphorylation of the membrane before immunoblotting (data not shown).

The recombinant full-length bOPN (rbOPN; Figure 4A, lane 6) presented a similar molecular weight in SDSPAGE to the dephosphorylated form of the milk mature bOPN (Figure 4, lane 4). The same observations were made for dephosphorylated human milk compared with the recombinant human OPN (rhOPN) protein (data not shown). As for rhOPN, the rbOPN remained unaffected by the Lambda PP treatment (data not shown). Phosphorylation was the major posttranslational modification observed for milk bOPN that affected migration on SDS-PAGE, because glycosylase treatment of bOPN did not introduce a noticeable shift in SDSPAGE, for treatment with either o-glycosylase or $N$ glycosylase (Figure 4A, lanes 2 and 3). However, bOPN was reactive to the staining of glycoconjugated proteins (Figure 4B), suggesting that the purified bOPN forms found in milk were glycosylated. Moreover, the upper band of the 40-kDa doublet was more effectively immunodetected by MAB193P after deglycosylation (Figure $4 \mathrm{~A}$, lane 2). Although the lower $40-\mathrm{kDa}$ isoform of the doublet was apparently less abundant, as it was barely detected by silver staining (Figure 4C), this isoform was a posttranslationally modified version of the upper band because the LC-MS/MS analysis of the doublet were identical (data not shown). Further experiments will define the extent of glycosylation of each protein form.

To characterize the bovine milk protein further, immunoblotting was performed using antibodies targeting different domains of the OPN protein. Analysis of bOPN using MAB193P, MAB194P, MAB197P, hOPN4 , and bOPN-117 showed that MAB193P was the only antibody recognizing the 2 major forms purified from milk, the intact and the truncated forms (Figure 5A). No detection by MAB194P was observed for bOPN, although hOPN was detected (data not shown). As 
A

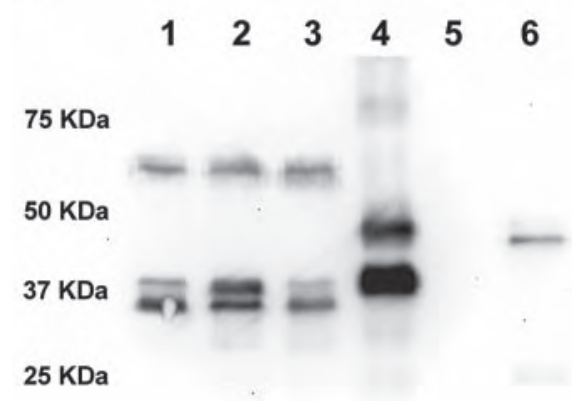

B

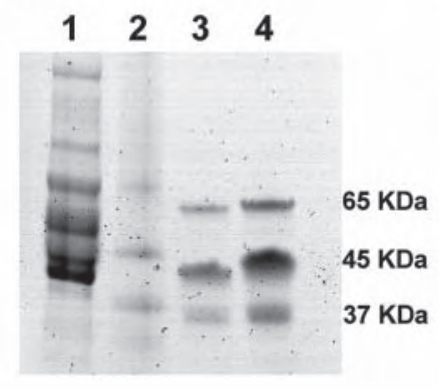

C

$\begin{array}{lll}1 & 2 & 3\end{array}$

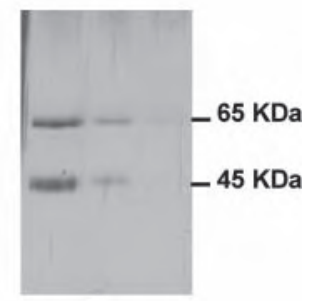

Figure 4. Posttranslational modifications affect bovine osteopontin (bOPN) detection in SDS-PAGE. (A) Immunoblotting using the $\mathrm{N}$-terminal MAB193P antibody following SDS-PAGE. An equivalent amount (500 ng) of untreated milk purified bOPN (lane 1) or treated with o-glycosylase (lane 2), $\mathrm{N}$-glycosylase (lane 3), or $200 \mathrm{ng}$ of Lambda protein phosphatase (PP)-treated bOPN (lane 4) was loaded in parallel with a bacterial culture $(5 \mu \mathrm{L})$ of the noninduced recombinant bOPN (lane 5 ), or induced by isopropyl- 3 -D-thio-galactoside for $4 \mathrm{~h}$ (lane 6 ). (B) Glycoprotein staining of milk purified bOPN. Glycoprotein marker (lane 1), molecular weight marker (lane 2), $5 \mu \mathrm{g}$ (lane 3), and 10 $\mu \mathrm{g}$ (lane 4) were fractionated by SDS-PAGE followed by glycoprotein staining. (C) Silver staining; 500, 250, or 50 ng of milk purified bOPN were fractionated by SDS-PAGE followed by silver staining.

LC-MS/MS detected the MAB194P region for both bOPN isoforms, the lack of detection is attributable to the limited similarity between the human and bovine regions (Figure 1). The 40-kDa bOPN was not detected with MAB197P or bOPN-117 antibodies (Figure 5, B and $\mathrm{C}$, respectively), which suggests a cleavage within this region. Indeed, this SNVQSPDATEEDFTSHIESEEMHDAPK region was not detected in the truncated isoform by proteomic analysis (Table 1). Neither MAB197P nor bOPN-117 antibodies detected the Cterminal portion of the protein on Western blot. The only polypeptide detected was a 28 -kDa milk peptide on the Western blot of milk sample tested with bOPN-117 (Figure 6C). This was not due to a specific detection but to cross-reactivity with an antibody present in the antibody preparation (bOPN-117 being a polyclonal antibody raised in rabbit), as confirmed by a competition assay. Using up to $100 \mu M$ of the peptide that raised bOPN-117 antibody did not prevent the detection of this $28-\mathrm{kDa}$ peptide, whereas using only $10 \mu \mathrm{M}$ in immunoblotting completely eliminated detection of both phosphorylated and dephosphorylated full-length proteins from milk or purified bOPN (data not shown). To determine the expected molecular weight of the Cterminal fragment that could be the proteolytic residue of the $40-\mathrm{kDa}$ isoform, thrombin was chosen because it cleaves at the border of the last peptide detected by LC-MS/MS. Indeed, the thrombin-recognizing "RS" site is adjacent to the bOPN-117 epitope (Figure 1). The thrombin-cleaved bOPN was analyzed by immunoblotting. As expected, cleavage eliminated bOPN detection by MAB197P (data not shown), confirming that the MAB197P epitope overlaps the thrombin cleav- age site (Figure 1). A C-terminal fragment at $18 \mathrm{kDa}$ was detected by bOPN-117, bOPN-121, and hOPN-4 following thrombin cleavage (Figure 6, A-C, respectively). The enzymatic treatment generated additional fragments. Interestingly, 2 additional C-terminal fragments were detected during the thrombin treatment. The concomitant cleavages were also observed in a time course experiment as the RS cleavage occurred slightly earlier within the first $5 \mathrm{~min}$ and generated the $18-\mathrm{kDa}$ fragment that was subsequently cleaved into 2 fragments (data not shown). These approximately 8- and $10-\mathrm{kDa}$ fragments were detected by bOPN-117 (data not shown) and hOPN-4 (Figure $6 \mathrm{~B}$, lanes 3 and 4 ), respectively, whereas the $18-\mathrm{kDa}$ fragment was detected by both antibodies. The bOPN-121 detected all (Figure $6 \mathrm{~B}$ and $6 \mathrm{C}$, lanes 3 and 4 ). These results suggest the presence of a second putative cleavage site located between the bOPN-117 and hOPN-4 epitopes (Figure $5 \mathrm{E})$. Because the peptide used to raise the bOPN-117 antibody is adjacent to the RS cleavage site (Figure 1), detection of the cleaved $18-\mathrm{kDa}$ fragment gave an estimate of the molecular weight of the C-terminal portion of the full-length $60-\mathrm{kDa}$ protein, which is apparently absent in 1 of the 2 major bOPN forms found in milk.

\section{DISCUSSION}

In humans, OPN displays a complex pattern of gene expression that is tissue- and physiological state-dependent. It has been speculated that the presence of OPN in human milk may play a role in the immunological development of breast-feeding infants (Nagatomo et al., 2004). However, pathologically elevated expression of 


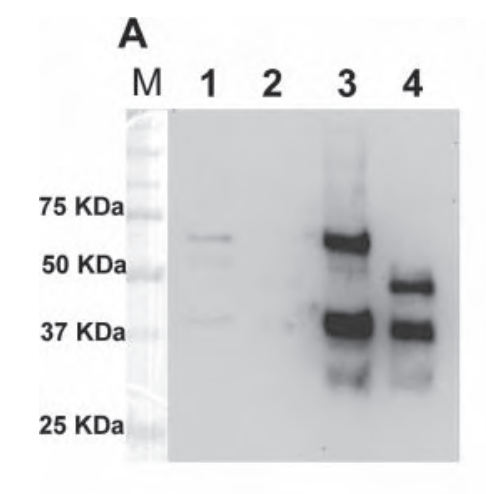

B
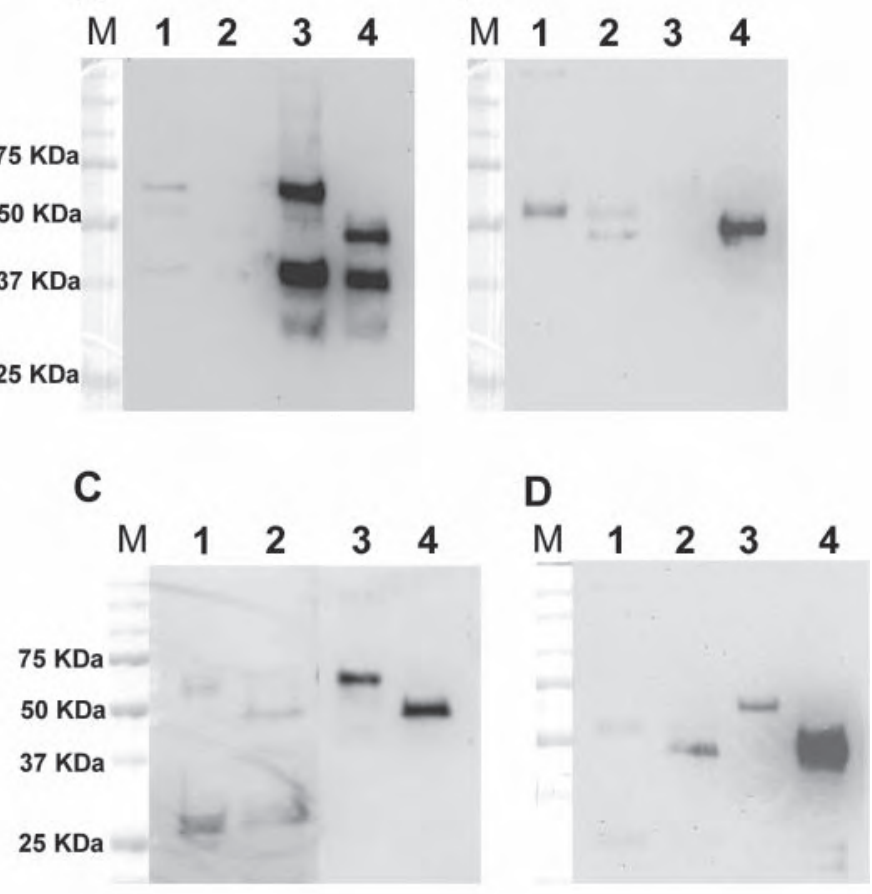

Figure 5. Detection comparison of different antibodies by immunoblotting. Immunodetection of SDS-PAGE was performed using MAB193P (A), MAB197P (B), bOPN-117 (C), and hOPN-4 (D). Milk (lane 1) and $10 \mu \mathrm{g}$ equivalent of dephosphorylated milk (lane 2), purified bOPN (1 $\mu \mathrm{g}$; lane 3), and $200 \mathrm{ng}$ equivalent of dephosphorylated bOPN (lane 4) were analyzed in a $12 \%$ SDS-PAGE. $\mathrm{M}=$ molecular weight marker (Precision Plus Protein All Blue Standards, Bio-Rad Laboratories Ltd., Mississauga, ON, Canada).

OPN has been linked to malignant transformation and metastasis of tumors. Furthermore, alternatively spliced isoforms have been detected in numerous cancer cells. Whereas only one isoform has been reported in human milk (Nagatomo et al., 2004), several have been found in bovine milk. We first speculated that the difference between human and bovine milk might be attributable to a problem of immunodetection. The antibody used in the Nagatomo et al. (2004) study to detect human OPN, specifically the 16-AA, anti-mouse O-17 epitope (Shinohara et al., 2008), differs from the human epitope by $4 \mathrm{AA}$ in a region encompassing 4 phosphorylation sites. Therefore, limited cross-reactivity between the anti-mouse epitope and the human epitope, together with the difference in phosphorylation status observed for bovine isoforms, could explain the absence of detection of truncated isoforms in that study. We nonetheless confirmed the findings of the Nagatomo et al. (2004) study, as we also found one isoform in human milk using the human-specific MAB193P antibody. Several isoforms were found in bovine milk. Thus, it was important to determine whether the OPN proteins in bovine milk show similarities to the human pathological isoforms. In the present study, we used SDS-PAGE to characterize 2 bOPN proteins purified from milk, a full-length $60-\mathrm{kDa}$ protein and a truncated $40-\mathrm{kDa}$ isoform. Proteomic analysis showed that the $40-\mathrm{kDa}$ protein consisted of the N-terminal portion of the full-length protein, and SPP1 gene expression revealed that the $40-\mathrm{kDa}$ protein was a truncated version of the full-length $60-\mathrm{kDa}$ protein, as no alternatively spliced transcript was detected. The proteomic profile of the $60-\mathrm{kDa}$ protein covered all translated exons. The proteomic and gene expression analyses corroborate the absence of alternative splicing for OPN in milk. Only one transcript was detected, regardless of the tissue. The secreted source of bovine milk OPN is still speculative but our preliminary analysis revealed that the major source might not originate from blood, because the plasma level of OPN is 50 times less than the quantity found in bovine milk (data not shown). In our previous study, SPP1 was expressed in somatic cells from both infected and healthy mammary glands (Alain et al., 2009), which suggests that milk immune cells secrete OPN. However, it does not account for the elevated level of OPN secreted in milk. The mammary gland remains the most obvious source of OPN. As confirmed by microarray analysis, intralobular epithelial and stromal cells analyzed following laser capture microdissection of the mammary gland expressed SPP1 (Casey et al., 2011). The transcript profile revealed that the epithelial cells express a high level SPP1, as much as the stromal tissue (e.g., log 2 values, refer to data set accession no. GSE18768 of Gene Expression Omnibus; www.ncbi.nlm.nih.gov/ geo). Among the putative major sources, the stroma may have an important contribution because its transcript signature was enriched with genes that encoded molecules important to signaling, extracellular matrix composition, and remodeling (Casey et al., 2011). The secreted origin of OPN thus comprises different sources (immune, stromal, endothelial, or epithelial cells) and the main cell type responsible for protein secretion is still speculative.

Glycosylation staining showed that all the isoforms in bovine milk were glycosylated. This was to be expected, because the 3 putative glycosylated residues are located at positions 131, 140, and 145 (Sørensen et al., 1995). No migration change of bOPN on SDS-PAGE was observed following the glycosylase treatment. This is in agreement with a study reporting that $o$-glycosylase and $N$-deglycosylase alone or in combination had no effect on hOPN migration on SDS-PAGE (Christensen et al., 2005). This contradicts a study by Kumura et al. (2004) showing that the apparent molecular weight of bOPN decreased following deglycosylation. The 

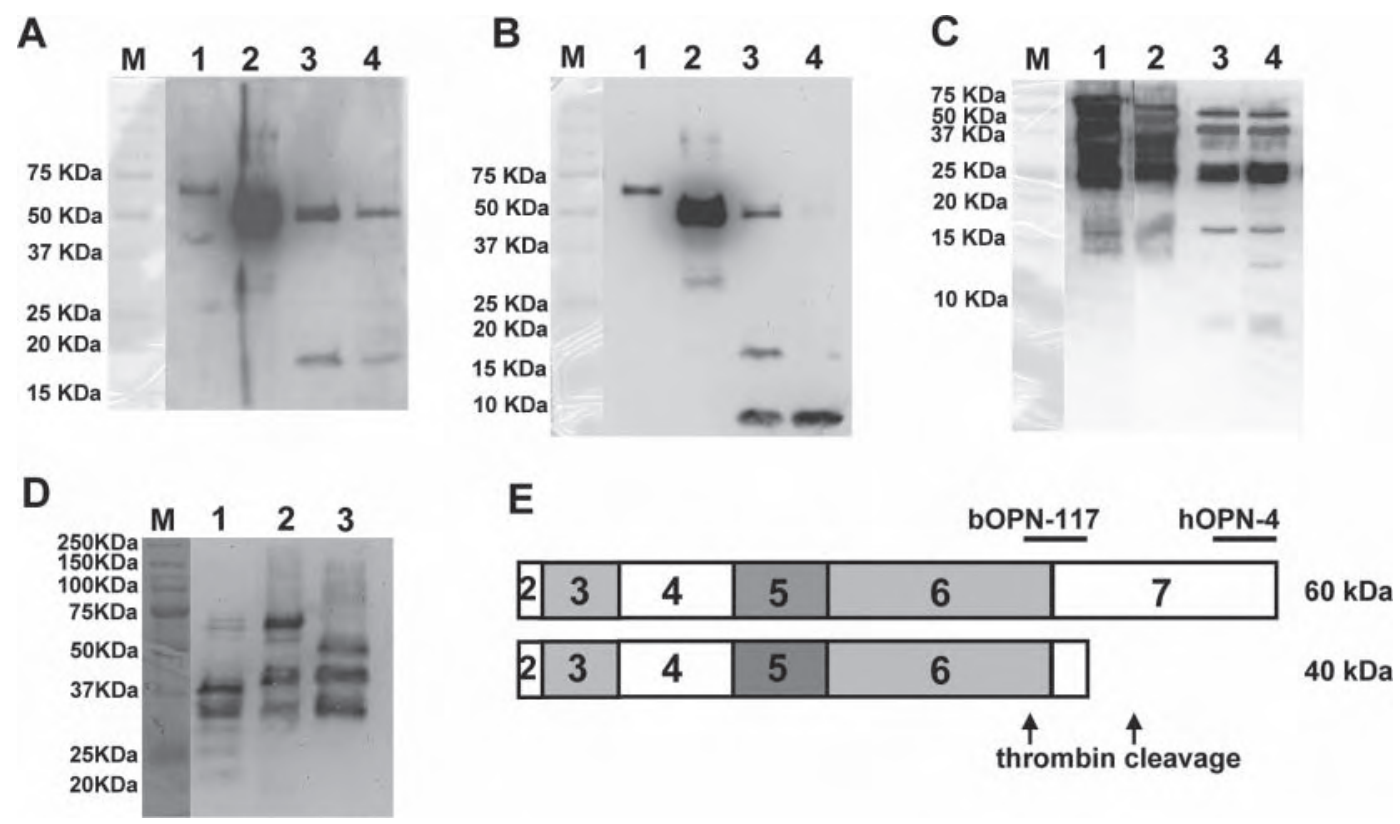

Figure 6. Detection of the bovine osteopontin (bOPN) cleaved forms. Immunoblotting using (A) bOPN-117, (B) hOPN-4, or (C) bOPN-121 antibodies. Purified bOPN (1 $\mu \mathrm{g}$ equivalent) was loaded as nontreated (lane 1), treated with Lambda protein phospatase (PP; lane 2), or treated with Lambda PP before thrombin for 15 (lane 3) or 60 min (lane 4). (D) Immunoblotting for high molecular weight proteins using bOPN-121: milk sample $(10 \mu \mathrm{g}$, lane 1), $1 \mu \mathrm{g}$ of purified bOPN (lane 2), or treated with Lambda PP (lane 3); M = molecular weight marker. (E) Schematic representation of exons 2 to 7 of the 2 major forms found in bovine milk and the putative thrombin cleavage sites. The bOPN-117 and hOPN-4 antibodies are mapped.

variation of molecular weight in that study may be explained by the absence of protease inhibitor and the use of a glycosylase prepared from Diplococcus pneumoniae, whereas the assays in the present study were performed with a highly purified recombinant glycosylase in the presence of protease inhibitors. Proteolysis could not be ruled out in that study.

The most noteworthy observation of the present study was the effect of phosphorylation on bOPN immunodetection. Although no phosphorylation was reported at the site of the corresponding MAB193P epitope ( $\mathrm{S} \varnothing-$ rensen et al., 1995), detection was influenced by the adjacent phosphorylation cluster. Whereas MAB193P, MAB197P, bOPN-117, and hOPN-4 detected the phosphorylated $60-\mathrm{kDa}$ bOPN, detection of the dephosphorylated forms was much more efficient (Figure 1). In general, detection of the dephosphorylated bOPN protein was superior, given that 5 times less dephosphorylated bOPN was loaded for an equivalent signal for the untreated sample (see, for example, Figure 5: lane 4, $200 \mathrm{ng}$ of dephosphorylated bOPN versus lane $3,1 \mu \mathrm{g}$ of intact counterpart). This effect could be due to the presence of phosphorylated serines within the epitope, as was the case for hOPN-4 and bOPN-117, or to their presence near the epitope, which would modify the accessibility or affinity of the antibody toward the epitope. Glycosylation is another factor affecting detec- tion. For instance, deglycosylated bOPN (Figure 4A, lane 2) was better detected by MAB193P, although the glycosylated sites are located in a different domain adjacent to the integrin (RDG) binding site (Figure 1). Of all the antibodies tested, MAB193P detected all bovine N-terminal OPN forms, whereas bOPN-121 efficiently detected all forms found in bovine milk, including the C-terminal fragments. For several antibodies tested in the present study, the extended phosphorylation state affected, and perhaps limited, bOPN detection. This aspect is underestimated in most of the studies reporting results of ELISA. As reported, the phosphorylation and glycosylation patterns of bOPN are tissue specific and differ from those in other species (Sørensen and Petersen, 1993a). The reactivity of a cross-species antibody needs to be verified, taking into account the secreted source of OPN and its phosphorylation state, as this may determine its usefulness for obtaining an objective evaluation of the expressed level.

We report here that OPN in milk is cleaved. The exact position of the cleavage site that generates the truncated $40-\mathrm{kDa}$ protein was not identified. The proteomic and immunoblotting analyses suggest that the cleavage site is above the peptide GDSVAYGLK on the protein sequence. Although the enzyme accounting for this proteolytic process is unknown, thrombin is considered, because it recognizes the RS site adjacent 
to this peptide. To our knowledge, thrombin has never been reported in the mammary gland but its expression was detected by microarray in lactating epithelial cells (Casey et al., 2011). Both the bovine prothrombin (GenBank accession no. M12049.1 from NCBI) and the coagulation factor II (accession no. NM_173877.1) are probed by the Affymetrix array and present expression values of $\log _{2}$ above threshold (data not shown). Thrombin can thus be considered as a putative enzyme. Other milk proteases may also be candidates, such as plasmin, a protease activated during infection and during involution. Matrix metalloproteinases (MMP) are important regulators of OPN biological activity, and hOPN contains 3 cleavage sites for MMP (Lund et al., 2009): $\mathrm{Gly}^{166}{ }^{1} \mathrm{Leu}^{167}$, which is located adjacent to an RS thrombin site and conserved between species (Agnihotri et al., 2001); $\mathrm{Ala}^{201}-\mathrm{Tyr}^{202}$, which is located in a region with limited similarity to the bovine sequence; and $\mathrm{Asp}^{210}-\mathrm{Leu}^{211}$, which is not present in bOPN (Figure 1). As the human Gly $^{166}$-Leu ${ }^{167}$ cleavage site is located in the peptide GDSVAYGLK, which was detected intact as part of the $40-\mathrm{kDa}$ protein, this cleavage site is not attributable to the truncated protein. However, the presence of bovine MMP with different proteolytic sites cannot be ruled out. It has been reported that OPN proteolytic fragmentation is a biological process having physiological importance (Takafuji et al., 2007); the presence of the $40-\mathrm{kDa}$ truncated protein in milk and the cleavage of the $\mathrm{C}$-terminal portion by thrombin are intriguing findings that warrant further investigation.

The hydrolyzed OPN in bovine milk may play a role in reducing crystal binding. Synthetic phosphopeptides corresponding to sequences in OPN inhibit the formation of calcium oxalate (Hoyer et al., 2001) and hydroxyapatite (Pampena et al., 2004). The role of OPN as an inhibitor of vascular calcification has been demonstrated (Steitz et al., 2002). The presence of OPN in milk may be related to control of the ectopic calcification of this calcium-rich fluid. Osteopontin is also known to be an immune marker, and hydrolysis may be one way to control its cytokine activity. In vitro and in vivo studies show that both thrombin- and MMP-cleaved OPN fragments possess greater activity than the full-length forms (Lund et al., 2009). We demonstrated that an additional thrombin cleavage occurred in the C-terminal fragment of bOPN. The biological relevance of this reaction in blood has not been elucidated. An interesting parallel can be drawn between OPN and chemerin. When chemerin, which circulates in blood as an inactive precursor, is cleaved, it induces the migration of inflammatory cells, whereas additional C-terminal processing reduces the production of proinflammatory mediators and macrophage activation (Cash et al., 2008). Cysteine protease processing of chemerin is re- quired to generate a ligand that inhibits inflammation through its cognate receptor, indicating that further cleavage introduces or reverses its biological function. It follows that the C-terminal part of OPN that links CD44 could be further transformed into fragmented ligands that would not exert an effect on inflammation. Further hydrolysis of the C-terminal fragment appears to be an additional control mechanism of CD44 interaction, a hypothesis that deserves further study. Whereas in blood, OPN lies at the interface between coagulation homeostasis and adaptive immunity (Qu and Chaikof, 2010), its role in milk remains poorly understood and warrants further investigation.

\section{CONCLUSIONS}

The aim of this study was to characterize the OPN secreted in bovine milk and to determine whether the different forms are the products of spliced variants. We characterized the milk bOPN isoforms by mass spectroscopy and analyzed the expressed transcripts. None were products of alternative splicing. The isoform found in milk is a truncated version of the main 60$\mathrm{kDa}$ secreted protein. A panel of 6 antibodies was used to profile all forms on SDS-PAGE and to examine the influence of phosphorylation status on immunodetection. Of all the antibodies tested, MAB193P detected all bovine N-terminal OPN forms, whereas bOPN-121 antibody efficiently detected all forms found in bovine milk, including the C-terminal fragments. This study confirms the presence of phosphorylated OPN in bovine milk but also provides evidence of truncated de- or hypo-phosphorylated isoforms, whose role and activity in milk remain to be elucidated.

\section{ACKNOWLEDGMENTS}

We thank Marcos di Falco at the Proteomic Platform, McGill University (Montreal, QC, Canada) along with the Génome Québec Innovation Centre (Montreal, QC, Canada) for technical help and support with data analysis. We thank Pierre Lacasse and Phillipe BernierDodier (Dairy and Swine Research and Development Centre, Agriculture and Agri-Food Canada, Sherbrooke, Québec, Canada) for the lactating mammary gland tissues. We are grateful to Weena Durand (Dairy and Swine Research and Development Centre) for providing technical assistance with immunoblotting. This research was supported by Agriculture and Agri-Food Canada (NOI 1276).

\section{REFERENCES}

Abraham, D. J., and A. J. Leo. 1987. Extension of the fragment method to calculate amino acid zwitterion and side chain partition coefficients. Proteins 2:130-152. 
Agnihotri, R., H. C. Crawford, H. Haro, L. M. Matrisian, M. C. Havrda, and L. Liaw. 2001. Osteopontin, a novel substrate for matrix metalloproteinase-3 (stromelysin-1) and matrix metalloproteinase-7 (matrilysin). J. Biol. Chem. 276:28261-28267.

Alain, K., N. A. Karrow, C. Thibault, J. St-Pierre, M. Lessard, and N. Bissonnette. 2009. Osteopontin: An early innate immune marker of Escherichia coli mastitis harbors genetic polymorphisms with possible links with resistance to mastitis. BMC Genomics 10:444.

Andersson, G., B. Ek-Rylander, K. Hollberg, J. Ljusberg-Sjolander, P. Lang, M. Norgard, Y. Wang, and S. J. Zhang. 2003. TRACP as an osteopontin phosphatase. J. Bone Miner. Res. 18:1912-1915.

Bayless, K. J., G. E. Davis, and G. A. Meininger. 1997. Isolation and biological properties of osteopontin from bovine milk. Protein Expr. Purif. 9:309-314.

Behrens, T. W., and R. R. Graham. 2011. TRAPing a new gene for autoimmunity. Nat. Genet. 43:90-91.

Bernier-Dodier, P., L. Delbecchi, G. F. Wagner, B. G. Talbot, and P. Lacasse. 2010. Effect of milking frequency on lactation persistency and mammary gland remodeling in mid-lactation cows. J. Dairy Sci. 93:555-564.

Butler, W. T. 1989. The nature and significance of osteopontin. Connect. Tissue Res. 23:123-136.

Casey, T., H. Dover, J. Liesman, L. Devries, M. Kiupel, M. Vandehaar, and K. Plaut. 2011. Transcriptome analysis of epithelial and stromal contributions to mammogenesis in three week prepartum cows. PLoS ONE 6:e22541.

Cash, J. L., R. Hart, A. Russ, J. P. Dixon, W. H. Colledge, J. Doran, A. G. Hendrick, M. B. Carlton, and D. R. Greaves. 2008. Synthetic chemerin-derived peptides suppress inflammation through ChemR23. J. Exp. Med. 205:767-775.

Chae, S., H. O. Jun, E. G. Lee, S. J. Yang, D. C. Lee, J. K. Jung, K. C. Park, Y. I. Yeom, and K. W. Kim. 2009. Osteopontin splice variants differentially modulate the migratory activity of hepatocellular carcinoma cell lines. Int. J. Oncol. 35:1409-1416.

Christensen, B., M. S. Nielsen, K. F. Haselmann, T. E. Petersen, and E. S. Sorensen. 2005. Post-translationally modified residues of native human osteopontin are located in clusters: Identification of 36 phosphorylation and five O-glycosylation sites and their biological implications. Biochem. J. 390:285-292.

Crivello, J. F., and E. Delvin. 1992. Isolation and characterization of a cDNA for osteopontin-k: A kidney cell adhesion molecule with high homology to osteopontins. J. Bone Miner. Res. 7:693-699.

Ek-Rylander, B., M. Flores, M. Wendel, D. Heinegard, and G. Andersson. 1994. Dephosphorylation of osteopontin and bone sialoprotein by osteoclastic tartrate-resistant acid phosphatase. Modulation of osteoclast adhesion in vitro. J. Biol. Chem. 269:14853-14856.

Fet, V., M. E. Dickinson, and B. L. Hogan. 1989. Localization of the mouse gene for secreted phosphoprotein 1 (Spp-1) (2ar, osteopontin, bone sialoprotein 1, 44-kDa bone phosphoprotein, tumorsecreted phosphoprotein) to chromosome 5, closely linked to Ric (Rickettsia resistance). Genomics 5:375-377.

He, B., M. Mirza, and G. F. Weber. 2006. An osteopontin splice variant induces anchorage independence in human breast cancer cells. Oncogene 25:2192-2202.

Hoyer, J. R., J. R. Asplin, and L. Otvos. 2001. Phosphorylated osteopontin peptides suppress crystallization by inhibiting the growth of calcium oxalate crystals. Kidney Int. 60:77-82.

Kabara, E., C. C. Kloss, M. Wilson, R. J. Tempelman, S. Sreevatsan, H. Janagama, and P. M. Coussens. 2010. A large-scale study of differential gene expression in monocyte-derived macrophages infected with several strains of Mycobacterium avium subspecies paratuberculosis. Brief. Funct. Genomics 9:220-237.

Kazanecki, C. C., D. J. Uzwiak, and D. T. Denhardt. 2007. Control of osteopontin signaling and function by post-translational phosphorylation and protein folding. J. Cell. Biochem. 102:912-924.

Kon, S., Y. Yokosaki, M. Maeda, T. Segawa, Y. Horikoshi, H. Tsukagoshi, M. M. Rashid, J. Morimoto, M. Inobe, N. Shijubo, A. F. Chambers, and T. Uede. 2002. Mapping of functional epitopes of osteopontin by monoclonal antibodies raised against defined internal sequences. J. Cell. Biochem. 84:420-432.
Kumura, H., A. Miura, E. Sato, T. Tanaka, and K. Shimazaki. 2004 Susceptibility of bovine osteopontin to chymosin. J. Dairy Res. 71:500-504

Kyte, J., and R. F. Doolittle. 1982. A simple method for displaying the hydropathic character of a protein. J. Mol. Biol. 157:105-132.

Laemmli, U. K. 1970. Cleavage of structural proteins during the assembly of the head of bacteriophage T4. Nature 227:680-685.

Liu, Y. J., D. Q. Zhang, X. M. Sui, and W. Tian. 2009. Overexpression of human osteopontin increases cell proliferation and migration in human embryo kidney-293 cells. Cell. Mol. Biol. Lett. 14:670-678.

Lund, S. A. C. M. Giachelli, and M. Scatena. 2009. The role of osteopontin in inflammatory processes. J. Cell Commun. Signal. $3: 311-322$.

Marsolais, F., A. Pajak, F. Yin, M. Taylor, M. Gabriel, D. M. Merino, V. Ma, A. Kameka, P. Vijayan, H. Pham, S. Huang, J. Rivoal, K. Bett, C. Hernandez-Sebastia, Q. Liu, A. Bertrand, and R. Chapman. 2010. Proteomic analysis of common bean seed with storage protein deficiency reveals up-regulation of sulfur-rich proteins and starch and raffinose metabolic enzymes, and down-regulation of the secretory pathway. J. Proteomics 73:1587-1600.

McKee, M. D., and A. Nanci. 1996. Secretion of osteopontin by macrophages and its accumulation at tissue surfaces during wound healing in mineralized tissues: A potential requirement for macrophage adhesion and phagocytosis. Anat. Rec. 245:394-409.

Mirza, M., E. Shaughnessy, J. K. Hurley, K. A. Vanpatten, G. A. Pestano, B. He, and G. F. Weber. 2008. Osteopontin-c is a selective marker of breast cancer. Int. J. Cancer 122:889-897.

Nagatomo, T., S. Ohga, H. Takada, A. Nomura, S. Hikino, M. Imura, K. Ohshima, and T. Hara. 2004. Microarray analysis of human milk cells: Persistent high expression of osteopontin during the lactation period. Clin. Exp. Immunol. 138:47-53.

Pampena, D. A., K. A. Robertson, O. Litvinova, G. Lajoie, H. A. Goldberg, and G. K. Hunter. 2004. Inhibition of hydroxyapatite formation by osteopontin phosphopeptides. Biochem. J. 378:1083-1087.

Plumer, A., H. Duan, S. Subramaniam, F. L. Lucas, S. Miesfeldt, A. K. Ng, and L. Liaw. 2008. Development of fragment-specific osteopontin antibodies and ELISA for quantification in human metastatic breast cancer. BMC Cancer 8:38.

Qu, Z., and E. L. Chaikof. 2010. Interface between hemostasis and adaptive immunity. Curr. Opin. Immunol. 22:634-642.

Richter, E. A., B. Vistisen, S. J. Maarbjerg, M. Sajan, R. V. Farese, and B. Kiens. 2004. Differential effect of bicycling exercise intensity on activity and phosphorylation of atypical protein kinase $\mathrm{C}$ and extracellular signal-regulated protein kinase in skeletal muscle. J. Physiol. 560:909-918.

Roseman, M. A. 1988. Hydrophobicity of the peptide C=O...H-N hydrogen-bonded group. J. Mol. Biol. 201:621-623.

Shin, Y. J., H. Lim Kim, J. S. Choi, J. Y. Choi, J. H. Cha, and M. Y Lee. 2010. Osteopontin: Correlation with phagocytosis by brain macrophages in a rat model of stroke. Glia 59:413-423.

Shinohara, M. L., H. J. Kim, J. H. Kim, V. A. Garcia, and H. Cantor. 2008. Alternative translation of osteopontin generates intracellular and secreted isoforms that mediate distinct biological activities in dendritic cells. Proc. Natl. Acad. Sci. USA 105:7235-7239.

Sørensen, E. S., P. Hojrup, and T. E. Petersen. 1995. Posttranslational modifications of bovine osteopontin: Identification of twenty-eight phosphorylation and three O-glycosylation sites. Protein Sci. 4:2040-2049.

Sørensen, E. S., and T. E. Petersen. 1993a. Phosphorylation, glycosylation and amino acid sequence of component PP3 from the proteose peptone fraction of bovine milk. J. Dairy Res. 60:535-542.

Sørensen, E. S., and T. E. Petersen. 1993b. Purification and characterization of three proteins isolated from the proteose peptone fraction of bovine milk. J. Dairy Res. 60:189-197.

Steitz, S. A., M. Y. Speer, M. D. McKee, L. Liaw, M. Almeida, H. Yang, and C. M. Giachelli. 2002. Osteopontin inhibits mineral deposition and promotes regression of ectopic calcification. Am. J. Pathol. 161:2035-2046. 
Takafuji, V., M. Forgues, E. Unsworth, P. Goldsmith, and X. W. Wang. 2007. An osteopontin fragment is essential for tumor cell invasion in hepatocellular carcinoma. Oncogene 26:6361-6371.

Tilli, T. M., V. Franco, B. Robbs, J. Wanderley, F. Silva, K. D. Mello, J. P. Viola, G. F. Weber, and E. R. Gimba. 2011. Osteopontin-c splicing isoform contributes to ovarian cancer progression. Mol. Cancer Res. 9:280-293.

Wang, K. X., and D. T. Denhardt. 2008. Osteopontin: Role in immune regulation and stress responses. Cytokine Growth Factor Rev. 19:333-345.

Wasiak, S., V. Legendre-Guillemin, R. Puertollano, F. Blondeau, M. Girard, E. de Heuvel, D. Boismenu, A. W. Bell, J. S. Bonifacino, and P. S. McPherson. 2002. Enthoprotin: A novel clathrin-asso- ciated protein identified through subcellular proteomics. J. Cell Biol. 158:855-862.

Weber, G. F., S. Zawaideh, S. Hikita, V. A. Kumar, H. Cantor, and S. Ashkar. 2002. Phosphorylation-dependent interaction of osteopontin with its receptors regulates macrophage migration and activation. J. Leukoc. Biol. 72:752-761.

Zhu, X. L., B. Ganss, H. A. Goldberg, and J. Sodek. 2001. Synthesis and processing of bone sialoproteins during de novo bone formation in vitro. Biochem. Cell Biol. 79:737-746.

Zohar, R., W. Lee, P. Arora, S. Cheifetz, C. McCulloch, and J. Sodek. 1997. Single cell analysis of intracellular osteopontin in osteogenic cultures of fetal rat calvarial cells. J. Cell. Physiol. 170:88-100. 